\title{
Editorial $^{1}$
}

Diferentes pesquisadores, nacionais e internacionais, colaboraram com nosso Boletim 65, referente ao segundo semestre de 2014. No fascículo há oito artigos, um relato de experiência, uma nota de aula e uma resenha.

Jadilson Ramos Almeida e Marcelo Câmara dos Santos, a partir das categorias de Marchand e Bednarz em livros didáticos canadenses, analisaram os problemas propostos para o ensino de equações polinomiais do $1^{\circ}$ grau com uma incógnita em livros aprovados no Programa Nacional do Livro Didático (PNLD) de 2011. Os autores apontaram a tendência nacional em explorar "falsos problemas", que nem sempre favorecem a passagem da aritmética à álgebra.

O livro didático também foi o foco do estudo que originou o artigo de Julia Calheiros Cartela de Araujo e Rosinalda Aurora de Melo Teles, mas se deslocou do sétimo ano para o ciclo de alfabetização. Um recorte a partir de 23 coleções aprovadas pelo PNLD de 2013 foi feito, de 1256 atividades, 86 tratavam a ideia de sequências temporais, originando duas subcategorias: rotina e ordenação de acontecimentos, havendo um predomínio da última (79\%), cujas atividades apresentavam o "antes" e "depois" similar ao modelo piagetiano.

Elizabeth Gomes Souza, Ana Virginia de Almeida Luna e Larissa Borges de Souza Lima, por meio de observação de uma atividade de modelagem matemática nos anos iniciais apontam três papeis que podem ser assumidos pelo professor na condução da produção discursiva dos alunos. Como aporte e conceitos teóricos Anna Sfard forneceu o subsídio à pesquisa para olhar a aprendizagem como forma de participação.

Sobre modelagem na formação inicial de professores de matemática estudos apontam a importância, do contato com a mesma nesta fase. Ana Paula dos Santos Malheiros buscou na obra de Paulo Freire subsídios para a compreensão da relevância de tal trabalho, que apesar de provocar insegurança, pode contribuir para o exercício da autonomia, para reflexões sobre os processos de ensino e aprendizagem de matemática, considerando questões como criticidade e o papel da matemática na sociedade.

Partindo da ideia de que errar é inevitável na prática escolar o artigo de Alina Galvão Spinillo, Auxiliadora Baraldi Pacheco, Juliana Ferreira Gomes e Luciano

\footnotetext{
${ }^{1}$ Boletim Gepem (Online) ISSN: 2176-2988 | n. 64 - Jan./Jun. 2014 (texto em diagramação).
} 
Cavalcanti trata do erro como algo didaticamente produtivo, por sua relevância na expressão e na aquisição de conhecimentos matemáticos. As concepções e propostas discutidas pelos autores são ilustradas com exemplos do cotidiano em situações controladas de investigação sobre resolução de problemas matemáticos por crianças.

Andresa Maria Justulin e Nelson Antonio Pirola inspirados na escala de atitudes de Brito (1996) adaptaram e validaram a partir das respostas de 373 alunos paulistas de ensino médio um questionário sobre a vida escolar e sobre a matemática. Baseado em desafios instigados pelas novas tecnologias digitais Arthur B. Powell apresenta resultados de um projeto que objetiva a construção colaborativa do conhecimento tecnológico, pedagógico e do conteúdo (CTPC) de professores de matemática.

De Lisboa, Hélia Oliveira e Ana Henriques, a partir de um quadro teórico que articula dois domínios (o conhecimento estatístico para ensinar e o pensamento estatístico), se debruçam sobre o conhecimento para ensinar investigações estatísticas de futuros professores do $3^{\circ}$ ciclo do ensino básico e do ensino secundário. Seus resultados mostram a pertinência do referencial teórico adotado e a potencialidade da discussão de episódios de sala de aula, na formação inicial de professores.

O relato de experiência elaborado pelas professoras Sabrine Costa Oliveira e Sandra Aparecida Fraga da Silva aborda uma oficina que explora transformações geométricas no plano em bordados de ponto cruz junto aos participantes do Projeto Mulheres Mil no Instituto Federal do Espírito Santo.

A nota de aula apresentada por Elisandra Bar de Figueiredo e Ivanete Zuchi Siple sugere uma abordagem para curvas polares, na qual questões interessantes surgem neste contexto sobre a necessidade da variação de 0 a $2 \pi$ para construir a rosácea $r=\sin (n \theta)$ e sobre a paridade de suas pétalas. O uso do software GeoGebra também é uma contribuição dessa nota de aula. Finalizando o número você poderá ler uma interessante resenha sobre o livro Indagações, reflexões e práticas em leituras e escritas na educação matemática (2013), feita pelo professor Paulo Soares Batista.

Aproveitar bem a sua leitura!

Pelo Comitê Editorial

Rosa Mazo Reis

Marcelo Almeida Bairral 